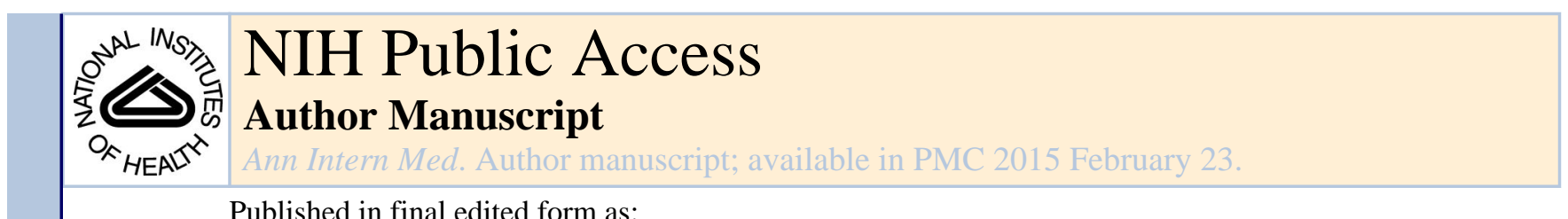

Published in final edited form as:

Ann Intern Med. 2011 October 4; 155(7): 415-424. doi:10.7326/0003-4819-155-7-201110040-00004.

\title{
A Prospective Evaluation of a Protocol for Magnetic Resonance Imaging of Patients With Implanted Cardiac Devices
}

\author{
Saman Nazarian, MD, Rozann Hansford, RN, MPH, Ariel Roguin, MD, PhD, Dorith Goldsher, \\ MD, Menekhem M. Zviman, PhD, Albert C. Lardo, PhD, Brian S. Caffo, PhD, Kevin D. Frick, \\ PhD, MA, Michael A. Kraut, MD, PhD, Ihab R. Kamel, MD, PhD, Hugh Calkins, MD, Ronald \\ D. Berger, MD, PhD, David A. Bluemke, MD, PhD, and Henry R. Halperin, MD, MA \\ Johns Hopkins University, Baltimore, Maryland; Rambam Medical Center, Technion Institute of \\ Technology, Haifa, Israel; and Radiology and Imaging Sciences, National Institutes of Biomedical \\ Imaging and Bioengineering, Bethesda, Maryland
}

\begin{abstract}
Background-Magnetic resonance imaging (MRI) is avoided in most patients with implanted cardiac devices because of safety concerns.
\end{abstract}

\footnotetext{
(C) 2011 American College of Physicians

Requests for Single Reprints: Saman Nazarian, MD, Johns Hopkins Hospital, 600 North Wolfe Street, Carnegie 592C, Baltimore, MD 21287; snazarian@jhmi.edu.

Current Author Addresses: Dr. Nazarian: Johns Hopkins Hospital, 600 North Wolfe Street, Carnegie 592C, Baltimore, MD 21287. Ms. Hansford and Dr. Zviman: Johns Hopkins University, 702 Rutland Avenue, Traylor 903, Baltimore, MD 21287.

Dr. Roguin: Cardiology Department, Rambam Medical Center, B. Rappaport Faculty of Medicine, Technion-Israel Institute of Technology, Haifa 31096, Israel.

Dr. Goldsher: MRI Unit, Radiology Department, Rambam Medical Center, B. Rappaport Faculty of Medicine, Technion-Israel Institute of Technology, Haifa 31096, Israel.

Dr. Lardo: Johns Hopkins University, 1042 Ross Building, Baltimore, MD 21287.

Dr. Caffo: Johns Hopkins Bloomberg School of Public Health, 615 North Wolfe Street, E3610, Baltimore, MD 21205.

Dr. Frick: Johns Hopkins Bloomberg School of Public Health, 624 North Broadway, Room 606, Baltimore, MD 21205.

Dr. Kraut: Johns Hopkins Hospital, 600 North Wolfe Street, Houck B-112B, Baltimore MD 21287.

Dr. Kamel: MRI Unit, Department of Radiology, Johns Hopkins University, Baltimore, MD 21287.

Drs. Calkins and Berger: Johns Hopkins Outpatient Center, 601 North Caroline Street, Baltimore, MD 21287.

Dr. Bluemke: Department of Radiology, National Institutes of Biomedical Imaging and Bioengineering, National Institutes of Health, 10 Center Drive, Bethesda, MD 20892.

Dr. Halperin: Johns Hopkins Hospital, 600 North Wolfe Street, Blalock 524A, Baltimore, MD 21287.
}

Potential Conflicts of Interest: Disclosures can be viewed at www.acponline.org/authors/icmje/ConflictOfInterestForms.do? msNum=M10-2403.

Reproducible Research Statement: Study protocol and statistical code: Available from Dr. Nazarian, snazarian@jhmi.edu. Data set: Certain portions of the analytic data set available to approved individuals through institutional review board approval and written agreements from Drs. Nazarian, snazarian@jhmi.edu and Halperin, hhalper@jhmi.edu.

Current author addresses and author contributions are available at www.annals.org.

Author Contributions: Conception and design: S. Nazarian, A. Roguin, M.M. Zviman, A.C. Lardo, I.R. Kamel, H. Calkins, H.R. Halperin.

Analysis and interpretation of the data: S. Nazarian, R. Hansford, A. Roguin, D. Goldsher, B.S. Caffo, K.D. Frick, I.R. Kamel, D.A. Bluemke, H.R. Halperin.

Drafting of the article: S. Nazarian, A. Roguin, B.S. Caffo, I.R. Kamel.

Critical revision of the article for important intellectual content: S. Nazarian, A. Roguin, D. Goldsher, M.M. Zviman, A.C. Lardo, B.S. Caffo, I.R. Kamel, H. Calkins, R.D. Berger, D.A. Bluemke, H.R. Halperin.

Final approval of the article: S. Nazarian, A. Roguin, D. Goldsher, B.S. Caffo, K.D. Frick, M.A. Kraut, I.R. Kamel, H. Calkins, H.R. Halperin. Provision of study materials or patients: A. Roguin, H. Calkins.

Statistical expertise: B.S. Caffo. Obtaining of funding: S. Nazarian.

Administrative, technical, or logistic support: R. Hansford, D. Goldsher, M.M. Zviman, M.A. Kraut, I.R. Kamel, D.A. Bluemke. Collection and assembly of data: S. Nazarian, R. Hansford, A. Roguin, D. Goldsher, I.R. Kamel, H. Calkins, D.A. Bluemke, H.R. Halperin. 
Objective-To define the safety of a protocol for MRI at the commonly used magnetic strength of $1.5 \mathrm{~T}$ in patients with implanted cardiac devices.

Design-Prospective nonrandomized trial. (ClinicalTrials.gov registration number: NCT01130896)

Setting-One center in the United States (94\% of examinations) and one in Israel.

Patients-438 patients with devices (54\% with pacemakers and $46 \%$ with defibrillators) who underwent 555 MRI studies.

Intervention-Pacing mode was changed to asynchronous for pacemaker-dependent patients and to demand for others. Tachy-arrhythmia functions were disabled. Blood pressure, electrocardiography, oximetry, and symptoms were monitored by a nurse with experience in cardiac life support and device programming who had immediate backup from an electrophysiologist.

Measurements-Activation or inhibition of pacing, symptoms, and device variables.

Results-In 3 patients ( $0.7 \%$ [ $95 \%$ CI, $0 \%$ to $1.5 \%$ ]), the device reverted to a transient back-up programming mode without long-term effects. Right ventricular (RV) sensing (median change, 0 $\mathrm{mV}$ [interquartile range $\{\mathrm{IQR}\},-0.7$ to $0 \mathrm{~V}]$ ) and atrial and right and left ventricular lead impedances (median change, $-2 \Omega[\mathrm{IQR},-13$ to $0 \Omega$ ], $-4 \Omega$ [IQR, -16 to $0 \Omega$ ], and $-11 \Omega$ [IQR, -40 to $0 \Omega$ ], respectively) were reduced immediately after MRI. At long-term follow-up (61\% of patients), decreased RV sensing (median, $0 \mathrm{mV}$, [IQR, -1.1 to $0.3 \mathrm{mV}$ ), decreased RV lead impedance (median, $-3 \Omega$, [IQR, -29 to $15 \Omega$ ]), increased RV capture threshold (median, $0 \mathrm{~V}$, $\mathrm{IQR}$, [0 to $0.2 \Omega]$ ), and decreased battery voltage (median, $-0.01 \mathrm{~V}$, IQR, -0.04 to $0 \mathrm{~V}$ ) were noted. The observed changes did not require device revision or reprogramming.

Limitations-Not all available cardiac devices have been tested. Long-term in-person or telephone follow-up was unavailable in 43 patients (10\%), and some data were missing. Those with missing long-term capture threshold data had higher baseline right atrial and right ventricular capture thresholds and were more likely to have undergone thoracic imaging. Defibrillation threshold testing and random assignment to a control group were not performed.

Conclusion-With appropriate precautions, MRI can be done safely in patients with selected cardiac devices. Because changes in device variables and programming may occur, electrophysiologic monitoring during MRI is essential.

Primary Funding Source-National Institutes of Health.

It is estimated that after implantation, up to $75 \%$ of patients with pacemakers and implantable cardioverter-defibrillators (ICDs) develop an indication for magnetic resonance image (MRI) examination owing to medical co-morbidities $(1,2)$. Previous small studies have reported the safety of MRI in patients with pacemakers and ICDs (3-12). A recent study investigated the safety of MRI in the setting of an MRI conditional pacemaker (13); the term "conditional" indicates a lack of known hazards in a specified MRI environment with specified conditions of use. However, the overall experience of MRI in the setting of standard devices is limited. All ICDs, and the overwhelming majority of currently implanted 
pacemakers, are considered a contraindication to MRI by the U.S. Food and Drug

Administration $(14,15)$ and by device manufacturers (16-18).

We performed a large prospective study to define the safety of an MRI protocol for patients with a pacemaker or ICD, using device selection based on previous in vitro, in vivo, and pilot clinical studies $(9,19)$ and device programming to minimize inappropriate activation or inhibition of therapies.

\section{Methods}

\section{Patient Selection}

The institutional review boards of Johns Hopkins University, Baltimore, Maryland, and Rambam Medical Center, Haifa, Israel, approved the protocol. Candidates with a clinical indication for MRI and an implantable device were referred from various primary and subspecialty physicians and were enrolled consecutively between February 2003 and April 2010. Patients with newly implanted ( $<6$ weeks) leads and those with abandoned or epicardial leads were excluded. Because most ICD systems lack asynchronous pacing capability, pacemaker-dependent patients with an ICD were also excluded. All patients gave written informed consent. The experience in the first 55 patients (68 MRI examinations) in the current study has been reported elsewhere (9). The study is registered at ClinicalTrials.gov (registration number NCT01130896).

\section{Assessment of Device and Lead Variable Changes}

Typical measures to assess appropriate device function include sensing, lead impedance, and capture threshold. "Sensing" is the ability of the system to sense an intracardiac intrinsic electrical signal. Adequate sensing amplitudes are necessary to trigger or inhibit device function in response to arrhythmia. "Lead impedance" is the opposition to flow of electrical current through the device circuitry and lead-tissue interface. Low or high lead impedance may indicate insulation breach or lead fracture, respectively. "Capture threshold" indicates the minimum energy required to consistently stimulate myocardial contraction. These measurements vary according to properties of the lead-tissue interface and the tissue. For example, lead impedance can display normal variations depending on the phase of breathing or time since implantation. Because of considerable expected variability, lead impedance variations exceeding $30 \%(20,21)$, capture threshold variations exceeding $50 \%(22)$, and sensing variations exceeding $40 \%(23,24)$ generally indicate clinically significant changes in lead performance.

Implantable devices are equipped with an electrical (reed) switch that responds to magnetic fields and is used for emergent asynchronous pacing or deactivation of therapies. Reed switch behavior in MRI scanners is unpredictable, but transient asynchronous pacing in this setting has not been associated with clinical sequelae $(6,9)$. Exposure to electromagnetic interference (EMI) may also cause implantable devices to revert to a back-up programming mode known as "power-on-reset." Power-on-reset events related to MRI have been observed and are generally resolved by reprogramming the device to pre-MRI settings (19). However, with power-on-reset, pacing is set to an inhibited mode and tachycardia therapies are 
enabled. In our study, we identified power-on-reset events by observation of pacing rate changes during MRI or by interrogation of the device after MRI. All outcomes deviating from routine were recorded as events. Two investigators, each patient's primary clinicians, and 2 clinicians without direct involvement in the study reviewed all events.

\section{Device Interrogation and Programming}

A registered nurse with experience in device programming and advanced cardiac life support was present during all scans, with immediate backup from a cardiac electrophysiologist. Baseline and immediate follow-up interrogations were performed within minutes of MRI. Long-term follow-up interrogation was recommended at 6 months. Device variables, including battery voltage, capture thresholds, impedances, and sensing, were recorded at each interrogation. Pacemaker dependence was assessed before MRI by transient inhibition of pacing. Pacing mode was programmed to asynchronous for patients without a stable intrinsic rhythm; an inhibited pacing mode was used for other patients. All other pacing and tachyarrhythmia functions were disabled. After completion of MRI, devices were reprogrammed to original settings. The Figure shows the experimental protocol $(9,25)$.

\section{Magnetic Resonance Imaging}

Imaging was performed with MRI scanners at the commonly used magnetic strength of 1.5 T. Avanto (Siemens, Erlangen, Germany) scanners were used at Johns Hopkins Hospital, and Signa (General Electric, Waukesha, Wisconsin) scanners were used at Rambam Medical Center. Patient symptoms were monitored by using the MRI scanner in-room speaker system. Noninvasive blood pressure was measured every 3 minutes. Continuous electrocardiography was monitored. Pulse oximetry was used as a surrogate for rhythm when electrocardiography showed MRI-related artifacts. Magnetic resonance imaging was performed according to standard institutional protocols for the region of interest.

The specific absorption rate (SAR) of MRI sequences, a measure of power absorbed per mass of tissue, was limited to less than $2.0 \mathrm{~W} / \mathrm{kg}$ in the first 55 patients (9). However, given the lack of association between SAR and changes in device variables $(6,26)$ and the unreliability of using SAR to guide MRI safety recommendations (27), no restrictions beyond the standard manufacturer SAR limits were applied in subsequent patients. Scans were repeated as clinically indicated.

\section{Statistical Analysis}

Continuous variables are summarized as medians and interquartile ranges (IQRs), and discrete variables are summarized as absolute numbers and percentages. Lead variables were compared by using the Wilcoxon signed-rank test with MRI as the unit of analysis. Absolute changes and percentages of change from baseline in device variables were calculated by MRI and summarized by medians and IQRs. The percentage of change from baseline was calculated by obtaining the median and IQR for the distribution of percentage of change relative to baseline values for device variables.

The number of comparisons for each device variable is unique, primarily because of variability in 1) the number of leads, 2) absence of intrinsic P/R waves, 3) presence of atrial 
arrhythmia, and 4) pulse widths during measurement of capture threshold at follow-up interrogation. However, data were missing for some interrogation records. The absence of intrinsic P/R waves and presence of atrial arrhythmia were not systematically recorded during follow-up interrogation. The proportion of missing data was therefore calculated on the basis of lead specifics (measurements that were expected given those specifics but were not collected) and includes data that are missing because of the absence of P/R waves, presence of atrial arrhythmia, or examination of capture threshold at a different pulse width during follow-up interrogation. If more than $5 \%$ of measurements for the follow-up variable were missing, patients for whom measurements were available were compared with those without measurements to assess systematic differences.

Relationships between immediate and long-term changes in device variables and the number of repeated scans, region of imaging, and lead length were assessed by using the nonparametric K-sample test on the median (for unordered groups) or a nonparametric test for trend (for ordered groups). All tests were 2-tailed, and analyses were performed by using Stata, version 10 (StataCorp, College Station, Texas).

\section{Role of the Funding Source}

The study was funded by the National Institutes of Health and the PJ Schafer Memorial Research Award. The funding sources had no role in study design, data collection, analysis, or interpretation, writing of the report, or the decision to submit the manuscript for publication.

\section{Results}

A total of 555 MRI examinations were performed in 438 patients, 237 (54\%) of whom had a pacemaker and 201 (46\%) had an ICD. Most examinations (94\%) were performed at Johns Hopkins Hospital. There were no differences between the study centers in patient age or sex, device models, or device indications. Table 1 shows the device models and the estimated number of active implants for each model in the United States, which total more than 1.8 million. Of 237 patients with pacemakers, 184 (78\%) received the device for symptomatic bradycardia and 53 (22\%) for complete heart block. Of 201 patients with an ICD, 191 (95\%) received the device for ischemic or non-ischemic cardiomyopathy, $9(4 \%)$ for right ventricular dysplasia, and $1(0.5 \%)$ for long QT syndrome. Fifty-three $(12 \%)$ patients had a biventricular pacing system. Median age was 66 years (IQR, 55 to 77 years), and 138 patients $(32 \%)$ were women.

Of the 555 MRI examinations, 222 (40\%) were of the brain, 122 (22\%) were of the spine, 89 $(16 \%)$ were of the heart, $72(13 \%)$ were of the abdomen or pelvis, and $50(9 \%)$ were of an extremity. Appendix Table 1 (available at www.annals.org) shows the indications for the studies. Examinations were repeated in $15 \%$ of patients ( $9 \%$ had 2 and $6 \%$ had 23$)$. The median time to repeated scan was 149 days (IQR, 61 to 283 days).

Baseline and immediate follow-up interrogation was performed in all 438 patients. Longterm follow-up results were available for 266 patients $(61 \%)$, with a median time to followup of 214 days (IQR, 64 to 478 days). Results of telephone follow-up in January 2011 of all 
patients without long-term interrogation revealed that $103(60 \%)$ were alive without device dysfunction and 26 (15\%) had died (of causes unrelated to the device). The remaining 43 patients (25\%) did not respond. Patients with and those without long-term follow-up did not differ in age, sex, type of or indication for device, region of the body that was scanned, or baseline device variables. With the exception of lower (better) right atrial capture thresholds in patients without long-term follow-up (median, $0.75 \mathrm{~V}$ [IQR, 0.5 to $1.0 \mathrm{~V}$ ] vs. $1 \mathrm{~V}$ [IQR, 0.6 to $1.2 \mathrm{~V}$ ] in those with follow-up; $P<0.001$ ), device variables obtained immediately after MRI did not differ in patients with and without long-term follow-up.

After loss to follow-up was accounted for, long-term right atrial capture threshold was missing in $10.8 \%$ of patients and long-term right ventricular capture threshold in $13.7 \%$. Compared with patients with follow-up, those with missing long-term right atrial capture threshold measurements had higher baseline right atrial capture thresholds (median, $1 \mathrm{~V}$ [IQR, 0.5 to $1.6 \mathrm{~V}$ ] vs. $0.8 \mathrm{~V}$ [IQR, 0.5 to $1.0 \mathrm{~V}$ ]; $P=0.030$ ) and higher right ventricular capture thresholds (median, $1 \mathrm{~V}$ [IQR, 0.8 to $1.4 \mathrm{~V}$ ] vs. $0.8 \mathrm{~V}$ [IQR, 0.6 to $1.0 \mathrm{~V}$ ]; $P=$ 0.006). In addition, patients with missing long-term right ventricular capture threshold measurements were more likely than those for whom these measurements were available to have undergone thoracic imaging (30\% vs. $19 \% ; P=0.003)$ and had higher baseline right atrial capture thresholds (median, $1.0 \mathrm{~V}$ [IQR, 0.8 to $2.0 \mathrm{~V}$ ] vs. $0.8 \mathrm{~V}$ [IQR, 0.5 to $1.0 \mathrm{~V}$ ]; $P$ $>0.001$ ) and right ventricular capture thresholds (median, $1.0 \mathrm{~V}$ [IQR, 0.8 to $2.0 \mathrm{~V}$ ] vs. 0.8 $\mathrm{V}$ [IQR, 0.6 to $1.0 \mathrm{~V}] ; P>0.001$ ). The Appendix (available at www.annals.org) presents the frequency of missing data in other measured variables (5\% to $10 \%$ missing) and baseline comparisons according to whether long-term follow-up data were available.

\section{Acute Safety and Device Function}

Three of the 438 patients experienced acute power-on-reset events $(0.7 \%$ [95\% CI, $0 \%$ to $1.5 \%])$. One of the 3 power-on-reset events occurred during cardiac MRI in a patient with a single-chamber ICD (Medtronic 7271, Minneapolis, Minnesota) that had been implanted in 1999. The ICD did not attempt to deliver tachyarrhythmia therapy, but the patient experienced a pulling sensation in his chest and the MRI examination was discontinued. The other 2 patients had pacemakers (Medtronic models 8968, implanted in 1997, and KDR401, implanted in 2003) and were undergoing brain and cervical spine examinations, respectively. Both patients had occasional pacing inhibition associated with programming reversion to the inhibited pacing mode, but they were not pacemaker-dependent and completed their MRI examinations. None of the 3 patients with acute power-on-reset events had device dysfunction during long-term follow-up (463, 105, and 416 days, respectively). The patient with device model 8968 completed 4 repeated MRI examinations uneventfully during the study.

During a routine generator exchange procedure 3 months after MRI, a patient with a pacemaker (Medtronic model KDR701, implanted in 2000) developed low impedance of the right ventricular lead requiring concurrent lead revision. Normal lead and device variables had been noted both immediately and 2 months after MRI and were suggestive of a perioperative insulation breach. Another patient with a pacemaker (St. Jude Medical device 5816, St. Paul, Minnesota, implanted in 2007) who had normal lead and device variables 
immediately and at long-term follow-up after each of 3 MRI examinations presented with a power-on-reset event 2 months after MRI but also shortly after proton-beam therapy; the event was therefore more likely to be associated with the proton-beam therapy (28). No other short-or long-term symptoms or problems related to device function were reported.

Device revision, programming, or interventions with MRI examination were not otherwise required. In pacemakers without magnet-mode programming capability, reed switch activation by MRI led to transient, asymptomatic, asynchronous pacing at the pacemakerspecific magnet rate. No unexpected or rapid activation of pacing was observed during MRI.

\section{Lead Sensing, Impedance, and Capture Thresholds at Immediate and Long-Term Follow- up}

No immediate or long-term change in variables in any patient was large enough to require lead or system revision or device reprogramming. Detailed comparisons of values obtained at baseline, immediately after MRI, and at long-term follow-up ( $61 \%$ of patients) revealed variations in several variables (Table 2). The distributions of immediate and long-term changes in device variables were within $20 \%$ of baseline for most participants. However, significant variability was noted, and some changes approached clinically important thresholds. Table 3 shows the distribution of the immediate and long-term percentage changes relative to baseline for each device variable.

\section{Determinants of Changes in Device Variables}

Immediate and long-term changes in device variables were compared after stratification by number of repeated scans, lead length, and region of imaging. For repeated scans, $9 \%$ of patients had 2 examinations and $6 \%$ had 3 or more examinations. Among patients with right atrial leads, lead lengths were $45 \mathrm{~cm}(25 \%) 46 \mathrm{~cm}(19 \%), 52 \mathrm{~cm}(44 \%), 53 \mathrm{~cm}(8 \%), 58 \mathrm{~cm}$ (2\%), and other (3\%); among those with right ventricular leads, lengths were $46 \mathrm{~cm}(1 \%)$, $52 \mathrm{~cm}(27 \%), 59 \mathrm{~cm}(35 \%), 64 \mathrm{~cm}(29 \%)$, and other (9\%); and among those with left ventricular leads, lengths were $78 \mathrm{~cm}(13 \%), 80 \mathrm{~cm}(20 \%), 86 \mathrm{~cm}(14 \%), 88 \mathrm{~cm} \mathrm{(18 \% ),} 90$ $\mathrm{cm}(30 \%)$, and other (5\%). Eighteen percent of examinations were thoracic, and $82 \%$ were nonthoracic.

Some evidence of decreased acute right ventricular $\mathrm{R}$-wave amplitude was noted with increasing scans in patients with more than 1 scan (median change, $0 \mathrm{mV}$ after the first scan, $0 \mathrm{mV}$ after the second scan, and $-0.3 \mathrm{mV}$ after the third scan; $P=0.059$ ). Some evidence for decreased long-term right ventricular R-wave amplitude was also noted with later scans in patients with more than 1 scan (median change, $0 \mathrm{mV}$ after the first scan; $-0.1 \mathrm{mV}$ after the second scan; and $-0.2 \mathrm{mV}$ after the third scan; $P=0.081$ ) (see Appendix Table 2, available at www.annals.org, for the IQRs for these variables).

Some evidence for decreased acute right atrial lead impedance was seen with decreasing lead length (median change, $-8 \Omega$ for $45-\mathrm{cm}$ leads, $-2 \Omega$ for $46-\mathrm{cm}$ leads, $0 \Omega$ for $52-\mathrm{cm}$ leads, $0 \Omega$ for $53-\mathrm{cm}$ leads, and $-4.5 \Omega$ for 58 -cm leads; $P=0.087$ ). Increasing right ventricular lead length was associated with decreased acute right ventricular $\mathrm{R}$-wave amplitude (median change, $0 \mathrm{mV}$ for $46-\mathrm{cm}$ leads, $0 \mathrm{mV}$ for $52-\mathrm{cm}$ leads, $-0.1 \mathrm{mV}$ for 59 - 
$\mathrm{cm}$ leads, and $0 \mathrm{mV}$ for 64 -cm leads; $P=0.033$ ) and decreased long-term right ventricular $\mathrm{R}$-wave amplitude (median change, $-0.1 \mathrm{mV}$ for 46 -cm leads, $0 \mathrm{mV}$ for 52-cm leads, 0.4 $\mathrm{mV}$ for $54-\mathrm{cm}$ leads, and $-0.4 \mathrm{mV}$ for $64-\mathrm{cm}$ leads; $P=0.022$ ). In contrast, shorter lead length was associated with an increased long-term right ventricular capture threshold (median change, $0.3 \mathrm{~V}$ for $46-\mathrm{cm}$ leads, $0 \mathrm{mV}$ for $52-\mathrm{cm}$ leads, $0.1 \mathrm{mV}$ for $59-\mathrm{cm}$ leads, and $0 \mathrm{mV}$ for $64-\mathrm{cm}$ leads; $P=0.014$ ) (see Appendix Table 2 for the IQRs for these variables).

Thoracic imaging was associated with decreased acute right ventricular R-wave amplitude (median change, $0 \mathrm{mV}$ vs. $0 \mathrm{mV}$ after nonthoracic scan [of nonzero differences, more decreases were associated with thoracic scans]; $P=0.044$ ), less decrease in acute right ventricular impedance (median change, $0 \Omega$ vs. $-5 \Omega$ after nonthoracic scan; $P=0.034$ ), and decreased acute battery voltage (median change, $0 \mathrm{~V}$ vs. $0 \mathrm{~V}$ after nonthoracic scan [of nonzero differences, more decreases were associated with thoracic scans]; $P=0.005$ ). Thoracic imaging was also associated with decreased long-term right ventricular R-wave amplitude (median change, $-1.4 \mathrm{mV}$ vs. $0 \mathrm{mV}$ after nonthoracic scan; $P=0.009$ ) and decreased long-term battery voltage (median change, $-0.05 \mathrm{~V}$ vs. $0 \mathrm{~V}$ after nonthoracic scan; $P=0.001$ ) (see Appendix Table 2 for the IQRs for these variables).

\section{Discussion}

We report results from what we believe is the largest prospective study of MRI in patients with implanted devices. In our study, the primary clinically significant event attributable to MRI was the occurrence of power-on-reset events in up to $1.5 \%$ of device recipients. During power-on-reset, the device is susceptible to inhibition of pacing output and activation of antitachycardia therapies $(8,19,29,30)$.

The large number of patients in our study provided adequate power to detect small changes in device variables. Of note, no change in an individual variable was large enough to require system revision or device reprogramming. Small changes in acute lead sensing, impedances, and capture thresholds after MRI in patients with devices have been reported $(6,8,26)$ and attributed to heating at the lead-tissue interface (31). Previous reports have also suggested that thoracic MRI may pose more risk owing to greater power deposition over the region containing the device $(8,32)$. The association between thoracic imaging and long-term right ventricular sensing in our study supports this hypothesis. Some evidence was also seen for associations between decreased lead sensing and repeated scans and between device variables and lead length. Statistical power for subgroup analyses was limited in our study, and the association of lead length and repeated scans with changes in device variables warrants further examination.

Overall, MRI was performed safely in all patients. When the device was located in the MRI field of view, image distortion, signal voids or bright areas, and poor fat suppression were noted. Selecting imaging planes perpendicular to the plane of the device generator, shortening the echo time, and using spin echo and fast spin echo sequences reduced the qualitative extent of artifact. Artifacts, when present, were limited to thoracic examinations, and the great majority of examinations yielded clinically useful information. 
In our protocol, candidate selection was based on prior safety studies; essentially, we enrolled patients with pacemaker and ICD generators manufactured after 1998 and 2000, respectively $(9,19)$. Patients with leads that had not matured $(<6$ weeks since implantation, during which the leads are prone to spontaneous dislodgement) and those with epicardial and abandoned leads (which are prone to heating) were excluded. The protocol specified programming an asynchronous pacing mode in pacemaker-dependent patients to avoid inappropriate inhibition of pacing due to detection of EMI. In contrast, an inhibited pacing mode was used for patients without pacemaker dependence to avoid inappropriate pacing due to tracking of EMI. Deactivation of other pacing functions ensured that sensing of EMI did not lead to unwarranted pacing. Tachyarrhythmia monitoring and therapies were deactivated to avoid delivery of unwarranted therapies.

In this study, 53 pacemaker-dependent patients without an ICD underwent MRI without safety issues. It is vital, however, to emphasize the need for appropriate programming of the device to an asynchronous mode, monitoring by qualified personnel, and availability of external pacing backup for such patients. If a power-on-reset event occurs, the device reverts to an inhibited pacing mode. Therefore, in pacemaker-dependent patients, the device may transiently cease pacing owing to EMI, and electrocardiographic monitoring and pulse oximetry are necessary so that the scan can be stopped if inhibition of pacing is noted. Pacemaker-dependent patients and ICD recipients with device generator models that seem to be susceptible to power-on-reset events (Table 1) should not have MRI. In addition, our findings should not be extrapolated to device models that were not evaluated in this study and lead configurations other than standard transvenous lead systems.

English-language MEDLINE searches performed on 2 January 2011 by using the Medical Subject Heading terms "pacemaker and MRI" and "defibrillator and MRI" yielded 367 articles. Of these articles, 15 were relevant and are summarized in Table 4. Initial experience with MRI at $0.5 \mathrm{~T}$ suggested the overall safety and possibility of pacing inhibition, transient reed switch activation, and battery voltage decrements (3-5). After demonstrating that patients with pacemakers can safety undergo MRI at $1.5 \mathrm{~T}$, Martin and colleagues (6) observed minute changes in capture threshold that were not associated with region of imaging, SAR, or time between pacemaker implantation and MRI. The safe performance of MRI at 1.5 T in ICD recipients was first reported by Gimbel and colleagues (8). Several relatively small studies have also reported overall safety $(7,10,30,33,34)$. Several investigators have reported a lack of change in troponin-I levels as a surrogate of myocardial damage after MRI $(11,12,35)$, and recent reports have demonstrated the overall safety of repeated MRI (36) and MRI without SAR restrictions in device recipients (26). Our study adds to the existing literature by providing substantial safety data on the largest number of patients and the most representative sampling of devices implanted to date.

Our study has limitations. Long-term in-person variables were obtained for $61 \%$ of patients. Long-term information obtained in person or by telephone follow-up was missing for 43 $(10 \%)$ of patients, and we cannot be certain whether device-related malfunctions or dysrhythmias occurred in these patients. With the exception of slightly better atrial capture threshold immediately after MRI in patients without long-term follow-up, however, patients with and without such follow-up did not differ in baseline characteristics and in device 
variables obtained at baseline and immediately after MRI. After loss to follow-up was accounted for, more than $5 \%$ of data were still missing for some device variables. Of note, long-term right atrial and right ventricular capture thresholds were missing in more than $10 \%$ of patients. Patients for whom these data were missing had higher baseline capture thresholds and were more likely to have undergone thoracic imaging. The patients referred for thoracic (cardiac) imaging were more likely than the overall sample to have advanced underlying cardiac disorders. Therefore, the baseline differences in variables for patients with missing long-term data may be associated with underlying cardiac diagnoses that led to referral for cardiac imaging. However, it is also possible that patients with missing data had greater changes in device variables (associated with more thoracic scans and higher baseline thresholds), and thus the level of risk may be underestimated.

Given previous demonstration of preserved ventricular fibrillation-defibrillation thresholds after MRI $(34,37)$, the questionable utility of routine testing (38), and serious associated side effects with routine testing (39), we did not perform defibrillation threshold testing in ICD patients undergoing MRI. Because MRI was clinically necessary in each patient and clinical equipoise supporting random assignment was lacking, we did not include a control group that did not have MRI. Although we studied a large number of devices overall, the numbers of each individual device model were small. In addition, device platforms are constantly evolving, and future platforms that differ from the ones that we tested may have interactions with EMI. Finally, the studies were performed in 1.5-T MRI scanners. These findings should not be extrapolated to scanners with higher or lower field strengths.

Given the advancing age of the population and expanding indications for pacing and prophylaxis of ventricular arrhythmia, the number of patients with cardiac devices will probably continue to increase. Many such patients stand to derive clinical benefit from the diagnostic power of MRI. Given the public health importance of this issue, device manufacturers should continue efforts to design permanent pacemaker and ICD systems with improved safety in the MRI environment (13).

In conclusion, using a protocol based on device selection and programming, MRI can be performed safely in patients with certain pacemaker and ICD systems. Given the potential for changes in device variables and programming, monitoring by device experts is necessary. The decision to perform MRI in each patient with an implantable device should be made by balancing the potential benefit of MRI against the attendant risks. Because thoracic MRI sequences have a greater effect on device variables and are more likely to result in artifacts, these sequences should be reserved for patients with an absolute clinical need.

\section{Acknowledgments}

Grant Support: By National Institutes of Health grants R01-HL64795 and R01-HL094610 to Dr. Halperin and K23-HL089333 to Dr. Nazarian, and a PJ Schafer Memorial Research Award.

\section{References}

1. Kalin R, Stanton MS. Current clinical issues for MRI scanning of pacemaker and defibrillator patients. Pacing Clin Electrophysiol. 2005; 28:326-8. [PubMed: 15826268] 
2. Levine GN, Gomes AS, Arai AE, Bluemke DA, Flamm SD, Kanal E, et al. American Heart Association Committee on Diagnostic and Interventional Cardiac Catheterization. Safety of magnetic resonance imaging in patients with cardiovascular devices: an American Heart Association scientific statement from the Committee on Diagnostic and Interventional Cardiac Catheterization, Council on Clinical Cardiology, and the Council on Cardiovascular Radiology and Intervention: endorsed by the American College of Cardiology Foundation, the North American Society for Cardiac Imaging, and the Society for Cardiovascular Magnetic Resonance. Circulation. 2007; 116:2878-91. [PubMed: 18025533]

3. Gimbel JR, Johnson D, Levine PA, Wilkoff BL. Safe performance of magnetic resonance imaging on five patients with permanent cardiac pacemakers. Pacing Clin Electrophysiol. 1996; 19:913-9. [PubMed: 8774821]

4. Sommer T, Vahlhaus C, Lauck G, von Smekal A, Reinke M, Hofer U, et al. MR imaging and cardiac pacemakers: in-vitro evaluation and in-vivo studies in 51 patients at $0.5 \mathrm{~T}$. Radiology. 2000; 215:869-79. [PubMed: 10831713]

5. Vahlhaus C, Sommer T, Lewalter T, Schimpf R, Schumacher B, Jung W, et al. Interference with cardiac pacemakers by magnetic resonance imaging: are there irreversible changes at 0.5 Tesla? Pacing Clin Electrophysiol. 2001; 24:489-95. [PubMed: 11341087]

6. Martin ET, Coman JA, Shellock FG, Pulling CC, Fair R, Jenkins K. Magnetic resonance imaging and cardiac pacemaker safety at 1.5-Tesla. J Am Coll Cardiol. 2004; 43:1315-24. [PubMed: 15063447]

7. Del Ojo JL, Moya F, Villalba J, Sanz O, Pavón R, Garcia D, et al. Is magnetic resonance imaging safe in cardiac pacemaker recipients? Pacing Clin Electrophysiol. 2005; 28:274-8. [PubMed: 15826258]

8. Gimbel JR, Kanal E, Schwartz KM, Wilkoff BL. Outcome of magnetic resonance imaging (MRI) in selected patients with implantable cardioverter defibrillators (ICDs). Pacing Clin Electrophysiol. 2005; 28:270-3. [PubMed: 15826257]

9. Nazarian S, Roguin A, Zviman MM, Lardo AC, Dickfeld TL, Calkins H, et al. Clinical utility and safety of a protocol for noncardiac and cardiac magnetic resonance imaging of patients with permanent pacemakers and implantable-cardioverter defibrillators at 1.5 tesla. Circulation. 2006; 114:1277-84. [PubMed: 16966586]

10. Sommer T, Naehle CP, Yang A, Zeijlemaker V, Hackenbroch M, Schmiedel A, et al. Strategy for safe performance of extrathoracic magnetic resonance imaging at 1.5 tesla in the presence of cardiac pacemakers in non-pacemaker-dependent patients: a prospective study with 115 examinations. Circulation. 2006; 114:1285-92. [PubMed: 16966587]

11. Naehle CP, Strach K, Thomas D, Meyer C, Linhart M, Bitaraf S, et al. Magnetic resonance imaging at 1.5-T in patients with implantable cardioverter-defibrillators. J Am Coll Cardiol. 2009; 54:549-55. [PubMed: 19643318]

12. Mollerus M, Albin G, Lipinski M, Lucca J. Cardiac biomarkers in patients with permanent pacemakers and implantable cardioverter-defibrillators undergoing an MRI scan. Pacing Clin Electrophysiol. 2008; 31:1241-5. [PubMed: 18811802]

13. Wilkoff BL, Bello D, Taborsky M, Vymazal J, Kanal E, Heuer H, et al. EnRhythm MRI SureScan Pacing System Study Investigators. Magnetic resonance imaging in patients with a pacemaker system designed for the magnetic resonance environment. Heart Rhythm. 2011; 8:65-73. [PubMed: 20933098]

14. Faris OP, Shein MJ. Government viewpoint: U.S. Food \& Drug Administration: pacemakers, ICDs and MRI [Editorial]. Pacing Clin Electrophysiol. 2005; 28:268-9. [PubMed: 15826256]

15. Faris OP, Shein M. Food and Drug Administration perspective: magnetic resonance imaging of pacemaker and implantable cardioverter-defibrillator patients [Editorial]. Circulation. 2006; 114:1232-3. [PubMed: 16982951]

16. Smith JM. Industry viewpoint: Guidant: pacemakers, ICDs, and MRI [Editorial]. Pacing Clin Electrophysiol. 2005; 28:264. [PubMed: 15826253]

17. Stanton MS. Industry viewpoint: Medtronic: pacemakers, ICDs, and MRI [Editorial]. Pacing Clin Electrophysiol. 2005; 28:265. [PubMed: 15826254] 
18. Levine PA. Industry viewpoint: St. Jude Medical: pacemakers, ICDs and MRI [Editorial]. Pacing Clin Electrophysiol. 2005; 28:266-7. [PubMed: 15826255]

19. Roguin A, Zviman MM, Meininger GR, Rodrigues ER, Dickfeld TM, Bluemke DA, et al. Modern pacemaker and implantable cardioverter/defibrillator systems can be magnetic resonance imaging safe: in vitro and in vivo assessment of safety and function at 1.5 T. Circulation. 2004; 110:47582. [PubMed: 15277324]

20. Sharif MN, Wyse DG, Rothschild JM, Gillis AM. Changes in pacing lead impedance over time predict lead failure. Am J Cardiol. 1998; 82:600-3. [PubMed: 9732887]

21. Danilovic D, Ohm OJ. Pacing impedance variability in tined steroid eluting leads. Pacing Clin Electrophysiol. 1998; 21:1356-63. [PubMed: 9670178]

22. Danilovic D, Ohm OJ. Pacing threshold trends and variability in modern tined leads assessed using high resolution automatic measurements: conversion of pulse width into voltage thresholds. Pacing Clin Electrophysiol. 1999; 22:567-87. [PubMed: 10234710]

23. Callans DJ, Hook BG, Marchlinski FE. Effect of rate and coupling interval on endocardial R wave amplitude variability in permanent ventricular sensing lead systems. J Am Coll Cardiol. 1993; 22:746-50. [PubMed: 8354808]

24. Chan CC, Lau CP, Leung SK, Tai YT, Leung WH, Lee I, et al. Comparative evaluation of bipolar atrial electrogram amplitude during everyday activities: atrial active fixation versus two types of single pass VDD/R leads. Pacing Clin Electrophysiol. 1994; 17:1873-7. [PubMed: 7845784]

25. Nazarian S, Halperin HR. How to perform magnetic resonance imaging on patients with implantable cardiac arrhythmia devices. Heart Rhythm. 2009; 6:138-43. [PubMed: 19121814]

26. Mollerus M, Albin G, Lipinski M, Lucca J. Magnetic resonance imaging of pacemakers and implantable cardioverter-defibrillators without specific absorption rate restrictions. Europace. 2010; 12:947-51. [PubMed: 20353963]

27. Baker KB, Tkach JA, Nyenhuis JA, Phillips M, Shellock FG, Gonzalez-Martinez J, et al. Evaluation of specific absorption rate as a dosimeter of MRI-related implant heating. J Magn Reson Imaging. 2004; 20:315-20. [PubMed: 15269959]

28. Gelblum DY, Amols H. Implanted cardiac defibrillator care in radiation oncology patient population. Int J Radiat Oncol Biol Phys. 2009; 73:1525-31. [PubMed: 18977096]

29. Gimbel JR. Unexpected asystole during 3 T magnetic resonance imaging of a pacemaker-dependent patient with a "modern" pacemaker. Europace. 2009; 11:1241-2. [PubMed: 19556252]

30. Halshtok O, Goitein O, Abu Sham'a R, Granit H, Glikson M, Konen E. Pacemakers and magnetic resonance imaging: no longer an absolute contraindication when scanned correctly. Isr Med Assoc J. 2010; 12:391-5. [PubMed: 20862817]

31. Luechinger R, Zeijlemaker VA, Pedersen EM, Mortensen P, Falk E, Duru F, et al. In vivo heating of pacemaker leads during magnetic resonance imaging. Eur Heart J. 2005; 26:376-83. [PubMed: 15618060]

32. Gimbel JR, Kanal E. Can patients with implantable pacemakers safely undergo magnetic resonance imaging? [Editorial]. J Am Coll Cardiol. 2004; 43:1325-7. [PubMed: 15063448]

33. Strach K, Naehle CP, Mühlsteffen A, Hinz M, Bernstein A, Thomas D, et al. Low-field magnetic resonance imaging: increased safety for pacemaker patients? Europace. 2010; 12:952-60. [PubMed: 20356915]

34. Burke PT, Ghanbari H, Alexander PB, Shaw MK, Daccarett M, Machado C. A protocol for patients with cardiovascular implantable devices undergoing magnetic resonance imaging (MRI): should defibrillation threshold testing be performed post-(MRI). J Interv Card Electrophysiol. 2010; 28:59-66. [PubMed: 20111895]

35. Naehle CP, Meyer C, Thomas D, Remerie S, Krautmacher C, Litt H, et al. Safety of brain 3-T MR imaging with transmit-receive head coil in patients with cardiac pacemakers: pilot prospective study with 51 examinations. Radiology. 2008; 249:991-1001. [PubMed: 19011193]

36. Naehle CP, Zeijlemaker V, Thomas D, Meyer C, Strach K, Fimmers R, et al. Evaluation of cumulative effects of MR imaging on pacemaker systems at 1.5 Tesla. Pacing Clin Electrophysiol. 2009; 32:1526-35. [PubMed: 19793358]

37. Coman JA, Martin ET, Sandler DA, Thomas JR. Implantable cardiac defibrillator interactions with magnetic resonance imaging at 1.5 Tesla [Abstract]. J Am Coll Cardiol. 2004; 43:138A. 
38. Glikson M, Luria D, Friedman PA, Trusty JM, Benderly M, Hammill SC, et al. Are routine arrhythmia inductions necessary in patients with pectoral implantable cardioverter defibrillators? $\mathrm{J}$ Cardiovasc Electrophysiol. 2000; 11:127-35. [PubMed: 10709706]

39. Frame R, Brodman R, Furman S, Kim SG, Roth J, Ferrick K, et al. Clinical evaluation of the safety of repetitive intraoperative defibrillation threshold testing. Pacing Clin Electrophysiol. 1992; 15:870-7. [PubMed: 1376899]

\section{Appendix. Missing Long-Term Follow-up Data}

After loss to follow-up was accounted for, more than 5\% of the data were missing for the following variables: acute right ventricular lead impedance (6.1\%), long-term P-wave amplitude (5.8\%), long-term right atrial capture threshold (10.8\%), long-term right ventricular lead impedance $(6.1 \%)$, long-term right ventricular lead R-wave amplitude (5.9\%), and long-term right ventricular capture threshold (13.7\%).

Patients with missing acute right ventricular lead impedance had higher P-wave amplitude at baseline than those without missing values (median, $2.8 \mathrm{mV}$ [IQR, 1.9 to $4.2 \mathrm{mV}$ ] vs. 3.6 $\mathrm{mV}$ [IQR, 2.8 to $5.0 \mathrm{mV}$ ]; $P=0.010$ ). Patients with missing long-term P-wave amplitude had lower right ventricular R-wave amplitude at baseline (median, $8.3 \mathrm{mV}$ [IQR, 5.4 to 12.0 $\mathrm{mV}$ ] vs. $11.7 \mathrm{mV}$ [IQR, 8.3 to $14.3 \mathrm{mV}$ ] among patients with long-term values; $P=0.032$ ). Patients with missing long-term right atrial capture threshold had higher right atrial capture threshold at baseline (median, $1 \mathrm{~V}$ [IQR, 0.5 to $1.6 \mathrm{~V}$ ] vs. $0.8 \mathrm{~V}$ [IQR, 0.5 to $1.0 \mathrm{~V}$ ]; $P=$ 0.030), lower right ventricular R-wave amplitude (median, $10 \mathrm{mV}$ [IQR, 6.3 to $13.0 \mathrm{mV}$ ] vs. $11.7 \mathrm{mV}$ [IQR, 8.3 to $14.5 \mathrm{mV}$ ]; $P=0.018$ ), and higher right ventricular capture threshold (median, $1 \mathrm{~V}$ [IQR, 0.8 to $1.4 \mathrm{~V}$ ] vs. $0.8 \mathrm{~V}$ [IQR, 0.6 to $1.0 \mathrm{~V}$ ]; $P=0.006$ ) at baseline compared with those without missing values. Patients with missing long-term right ventricular lead impedance were less likely to be male than those for whom values were available (52\% vs. $70 \% ; P=0.042)$ and were younger at baseline (median age, 60 years [IQR, 38 to 75 years] vs. 66 years [IQR, 55 to 77 years]; $P=0.034$ ). Patients with missing long-term right ventricular R-wave amplitude were more likely to have undergone thoracic imaging (33\% vs. $17 \% ; P=0.018$ ) and to be younger (median age, 53 years [IQR, 37 to 69 years] vs. 67 years [IQR, 56 to 77 years]; $P=0.001$ ) at baseline than those without missing values.

Patients with missing long-term right ventricular capture threshold were less likely to be male (58\% vs. $70 \% ; P=0.031$ ), were more likely to have undergone thoracic imaging ( $30 \%$ vs. $19 \% ; P=0.003$ ), had higher right atrial capture thresholds (median, $1.0 \mathrm{~V}$ [IQR, 0.8 to $2.0 \mathrm{~V}$ ] vs. $0.8 \mathrm{~V}$ [IQR, 0.5 to $1.0 \mathrm{~V}$; $P=0.001$ ), had lower right ventricular R-wave amplitude (median, $10 \mathrm{mV}$ [IQR, 6.8 to $13.4 \mathrm{mV}$ ] vs. $11.7 \mathrm{mV}$ [IQR, 8.3 to $14.5 \mathrm{mV}$ ]; $P=$ 0.044 ), and higher right ventricular capture threshold (median, $1.0 \mathrm{~V}$ [IQR, 0.8 to $2.0 \mathrm{~V}$ ] vs. $0.8 \mathrm{~V}$ [IQR, 0.6 to $1.0 \mathrm{~V}$ ]; $P=0.001$ ) at baseline than those without missing values. 


\section{Appendix Table 1}

Indications for Magnetic Resonance Imaging

\begin{tabular}{|c|c|}
\hline Region & Indications \\
\hline Brain $(40 \%)$ & $\begin{array}{l}\text { Mass, } 38 \% \text {; mental status change, } 27 \% \text {; stroke, } 15 \% \text {; persistent headache or dizziness, } 12 \% \text {; } \\
\text { seizure, } 4 \% \text {; other, } 5 \%\end{array}$ \\
\hline Spine $(22 \%)$ & Radiculopathy, $78 \%$; mass or abscess, $22 \%$ \\
\hline Heart $(16 \%)$ & $\begin{array}{l}\text { Viability, } 61 \% \text {; possible right ventricular dysplasia, } 10 \% \text {; aortic disease, } 9 \% \text {; sarcoidosis, } \\
10 \% \text {; congenital malformations, } 5 \% \text {; infiltrative myopathies, } 5 \%\end{array}$ \\
\hline $\begin{array}{l}\text { Abdomen or pelvis } \\
(13 \%)\end{array}$ & $\begin{array}{l}\text { Hepatic mass, } 32 \% \text {; renal mass, } 21 \% \text {; prostate mass, } 13 \% \text {; pancreatic mass, } 12 \% \text {; renal } \\
\text { artery stenosis, } 8 \% \text {; bladder mass, } 7 \% \text {; uterine or ovarian mass, } 7 \%\end{array}$ \\
\hline Extremity $(9 \%)$ & Joint or muscle pain, $80 \%$; osteomyelitis, $20 \%$ \\
\hline
\end{tabular}

\section{Appendix Table 2}

Determinants of Changes in Device Variables*

\begin{tabular}{|c|c|c|c|}
\hline Variable & Repeated Scans & Lead Length & Region of Imaging \\
\hline $\begin{array}{l}\text { Acute right ventricular R- } \\
\text { wave amplitude, } m V\end{array}$ & $\begin{array}{l}\text { First: } 0(-1.0 \text { to } 0) \\
\text { Second: } 0(-0.7 \text { to } 0.05) \\
\text { Third: }-0.3(-0.9 \text { to } 0) \\
P=0.059\end{array}$ & $\begin{array}{l}46 \mathrm{~cm}: 0(-0.5 \text { to } 0.1) \\
52 \mathrm{~cm}: 0(-0.4 \text { to } 0) \\
59 \mathrm{~cm}:-0.1(-1 \text { to } 0) \\
64 \mathrm{~cm}: 0(-0.8 \text { to } 0.7) \\
P=0.033\end{array}$ & $\begin{array}{l}\text { Nonthoracic: } 0(-0.6 \text { to } 0) \\
\text { Thoracic: } 0 \text { ( }-0.8 \text { to } 0) \\
P=0.044\end{array}$ \\
\hline $\begin{array}{l}\text { Acute atrial lead } \\
\text { impedance, } \Omega\end{array}$ & No association & $\begin{array}{l}45 \mathrm{~cm}:-8(-17 \text { to } 0) \\
46 \mathrm{~cm}:-2(-10 \text { to } 0) \\
52 \mathrm{~cm}: 0(-10 \text { to } 2) \\
53 \mathrm{~cm}: 0(-18 \text { to } 5) \\
58 \mathrm{~cm}:-4.5(-15 \text { to } 7) \\
P=0.087\end{array}$ & No association \\
\hline $\begin{array}{l}\text { Acute right ventricular } \\
\text { lead impedance, } \Omega\end{array}$ & No association & No association & $\begin{array}{l}\text { Nonthoracic: }-5(-18 \text { to } 0) \\
\text { Thoracic: } 0 \text { ( }-14 \text { to } 0) \\
P=0.034\end{array}$ \\
\hline Acute battery voltage, $V$ & No association & No association & $\begin{array}{l}\text { Nonthoracic: } 0(0 \text { to } 0) \\
\text { Thoracic: } 0 \text { ( } 0 \text { to } 0) \\
P=0.005\end{array}$ \\
\hline $\begin{array}{l}\text { Long-term right } \\
\text { ventricular R-wave } \\
\text { amplitude, } m V\end{array}$ & $\begin{array}{l}\text { First: } 0(-0.4 \text { to } 0.4) \\
\text { Second: }-0.1 \text { ( }-0.8 \text { to } 0.6) \\
\text { Third: }-0.2(-0.8 \text { to } 1.8) \\
P=0.081\end{array}$ & $\begin{array}{l}46 \mathrm{~cm}:-0.1(-0.8 \text { to } 1) \\
52 \mathrm{~cm}: 0(-0.7 \text { to } 1.8) \\
59 \mathrm{~cm}: 0.4(-3.1 \text { to } 1.1) \\
64 \mathrm{~cm}:-0.4(-1.1 \text { to } 1.2) \\
P=0.022\end{array}$ & $\begin{array}{l}\text { Nonthoracic: } 0 \text { ( }-0.8 \text { to } 0.4) \\
\text { Thoracic: }-1.4 \text { ( }-2.5 \text { to } 0) \\
P=0.009\end{array}$ \\
\hline $\begin{array}{l}\text { Long-term right } \\
\text { ventricular lead } \\
\text { impedance, } \Omega\end{array}$ & No association & No association & No association \\
\hline $\begin{array}{l}\text { Long-term right } \\
\text { ventricular capture } \\
\text { threshold, } V\end{array}$ & No association & $\begin{array}{l}46 \mathrm{~cm}: 0.3(0.3 \text { to } 0.5) \\
52 \mathrm{~cm}: 0(-0.1 \text { to } 0.3) \\
59 \mathrm{~cm}: 0.1(0 \text { to } 0.3) \\
64 \mathrm{~cm}: 0(-0.2 \text { to } 0.2) \\
P=0.014\end{array}$ & No association \\
\hline $\begin{array}{l}\text { Long-term battery voltage, } \\
V\end{array}$ & No association & No association & $\begin{array}{l}\text { Nonthoracic: } 0(-0.03 \text { to } 0) \\
\text { Thoracic: }-0.05(-0.2 \text { to }-0.01) \\
P<0.001\end{array}$ \\
\hline
\end{tabular}

Values are medians (interquartile ranges). 


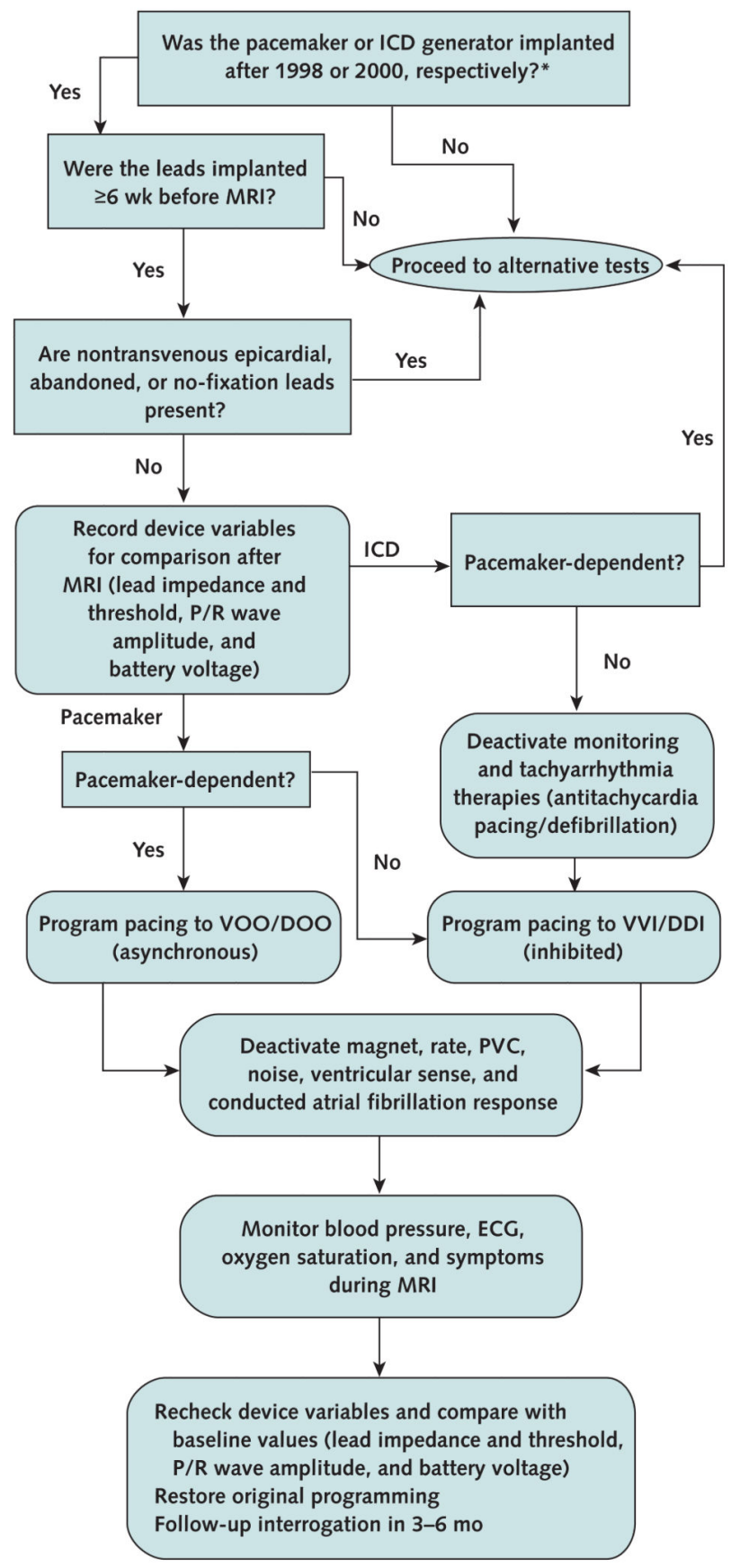

Figure. Safety protocol for MRI in the setting of implanted cardiac devices

DDI = dual-chamber inhibited pacing without atrial tracking; $\mathrm{DOO}=$ dual-chamber asynchronous pacing; ECG = electrocardiography; ICD = implantable cardioverterdefibrillator; $\mathrm{MRI}=$ magnetic resonance imaging; $\mathrm{PVC}=$ premature ventricular contraction; $\mathrm{VOO}=$ ventricular asynchronous pacing; VVI = ventricular inhibited pacing.

* Adapted from reference 9. 

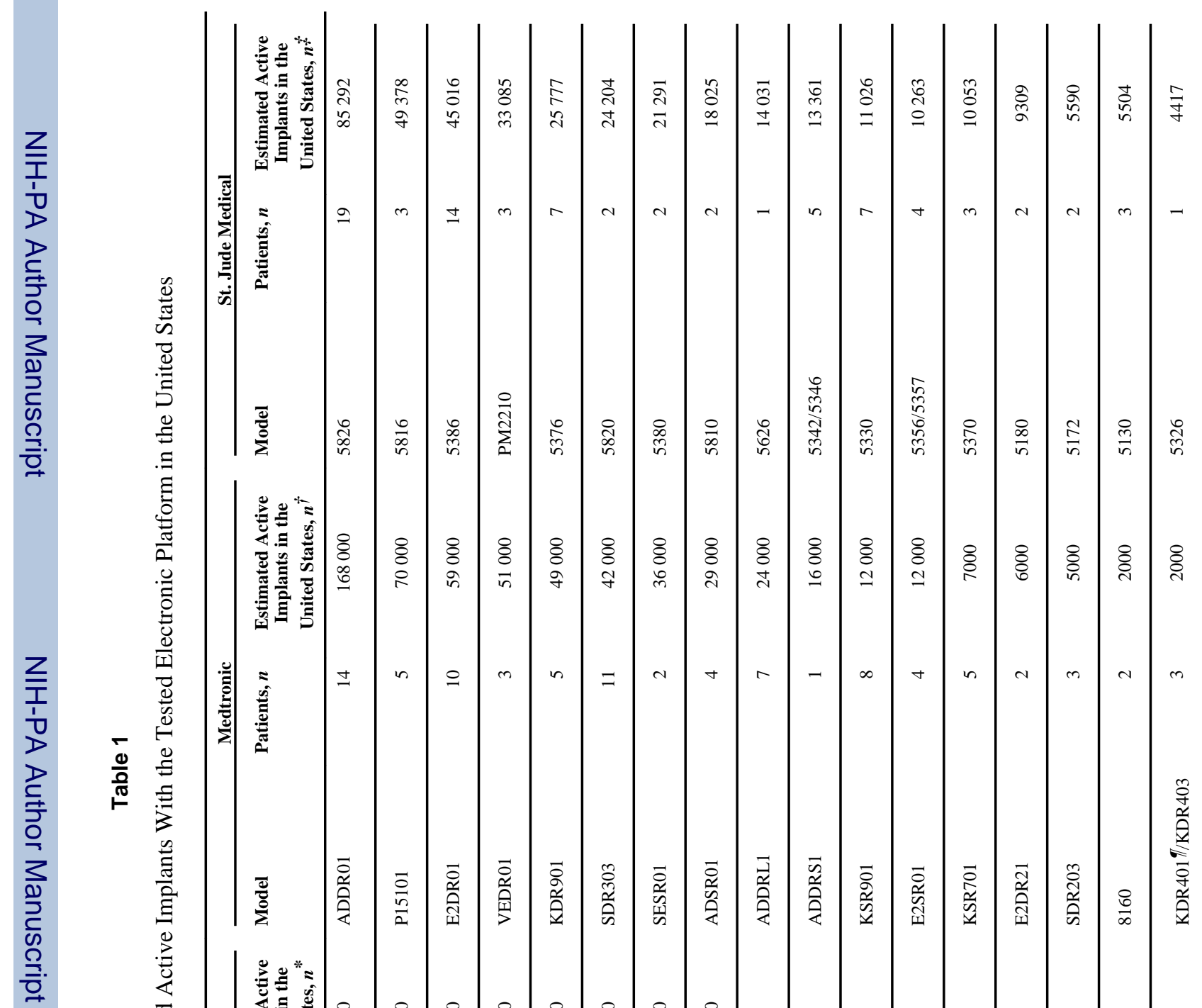

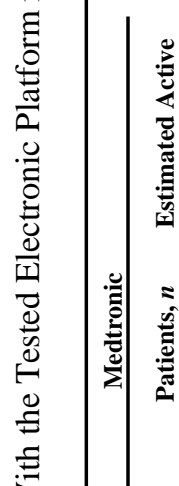

D.

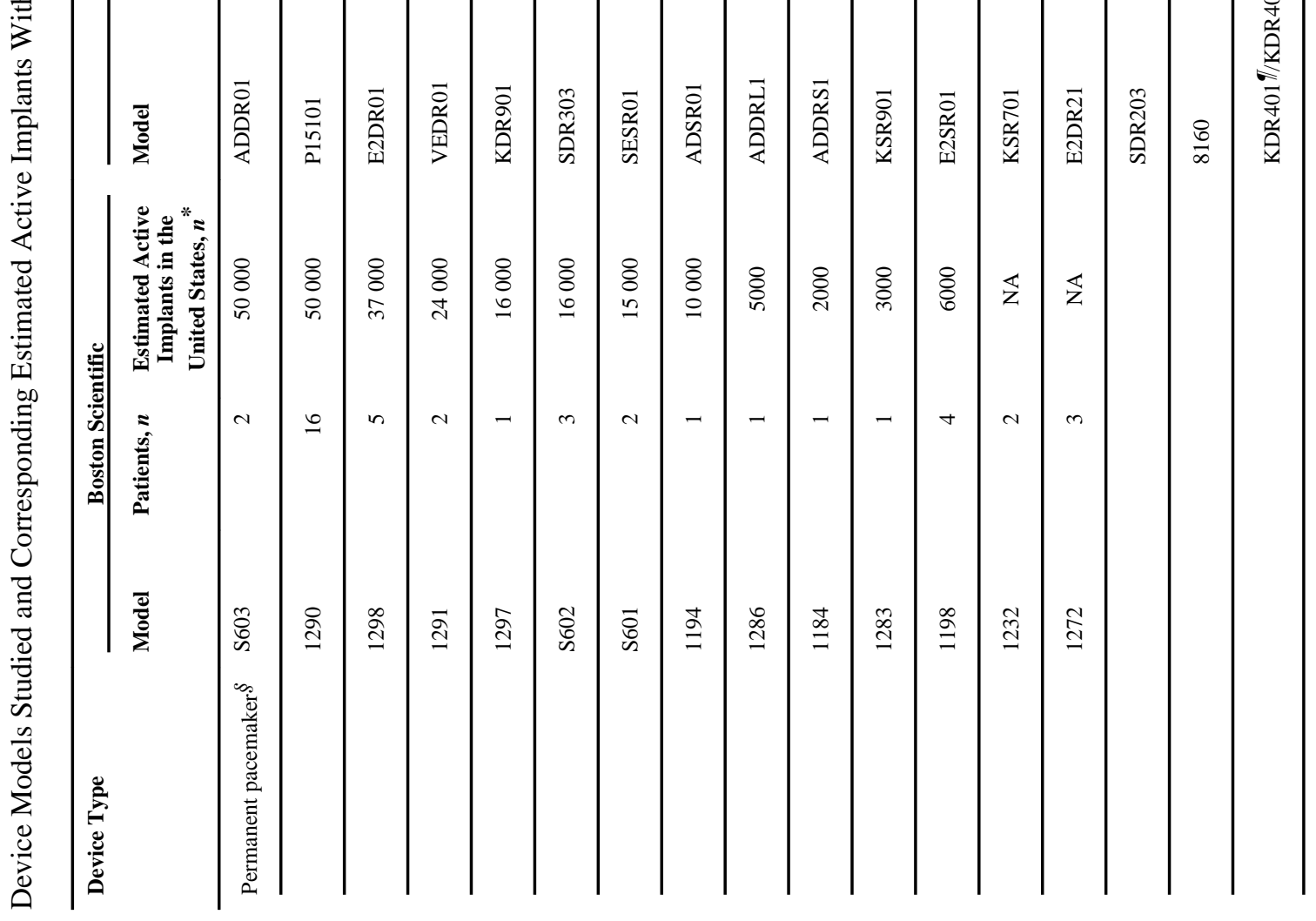



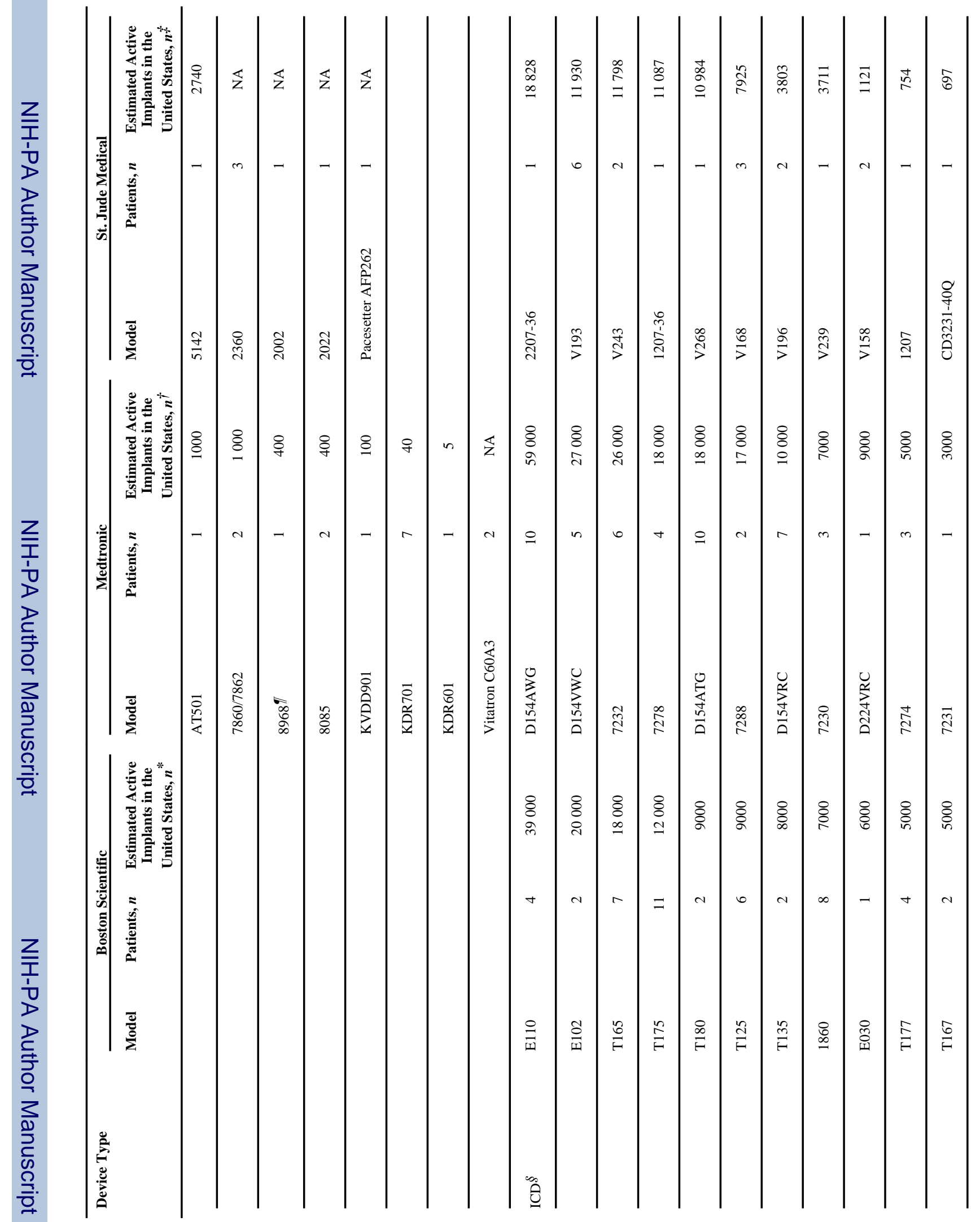


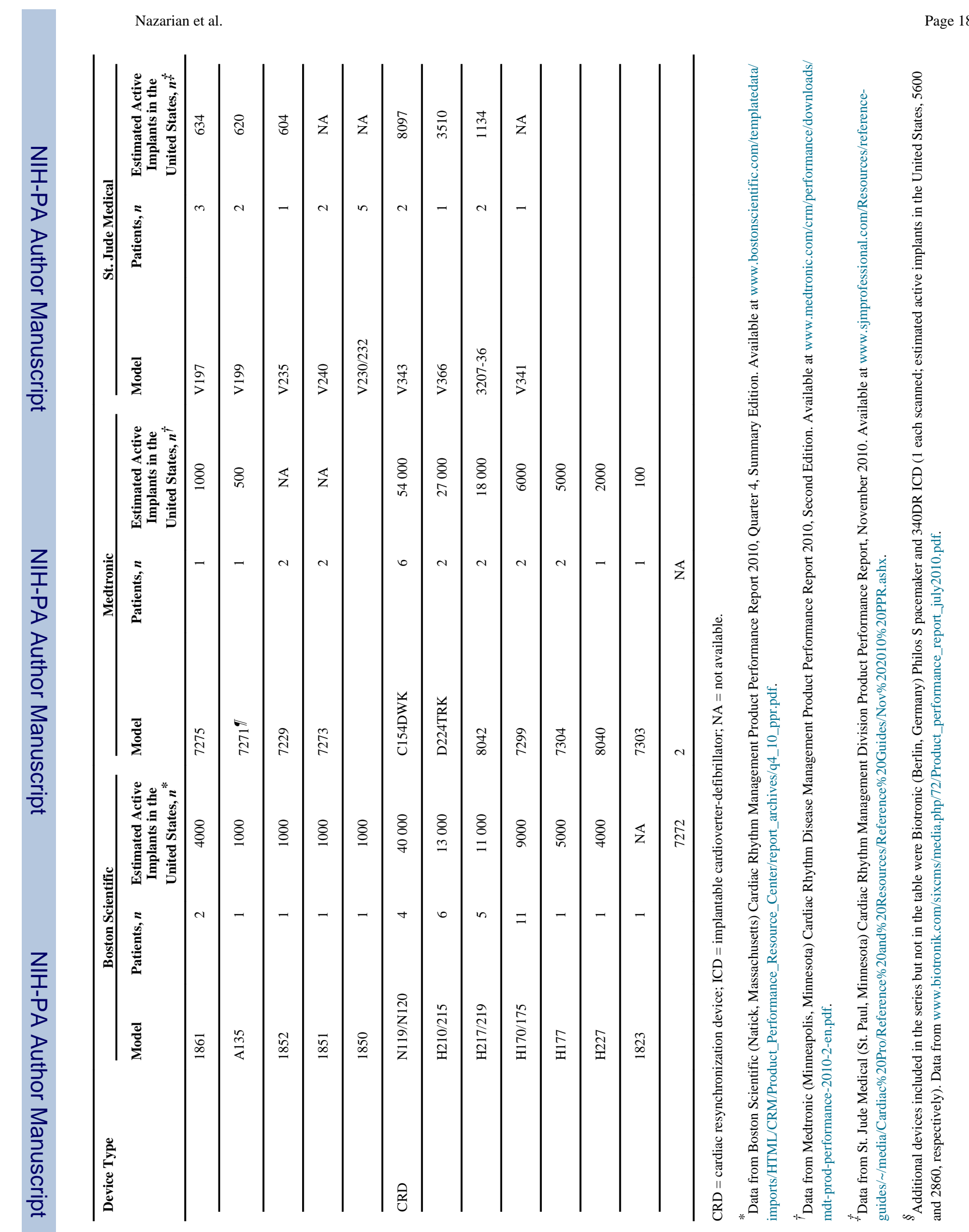




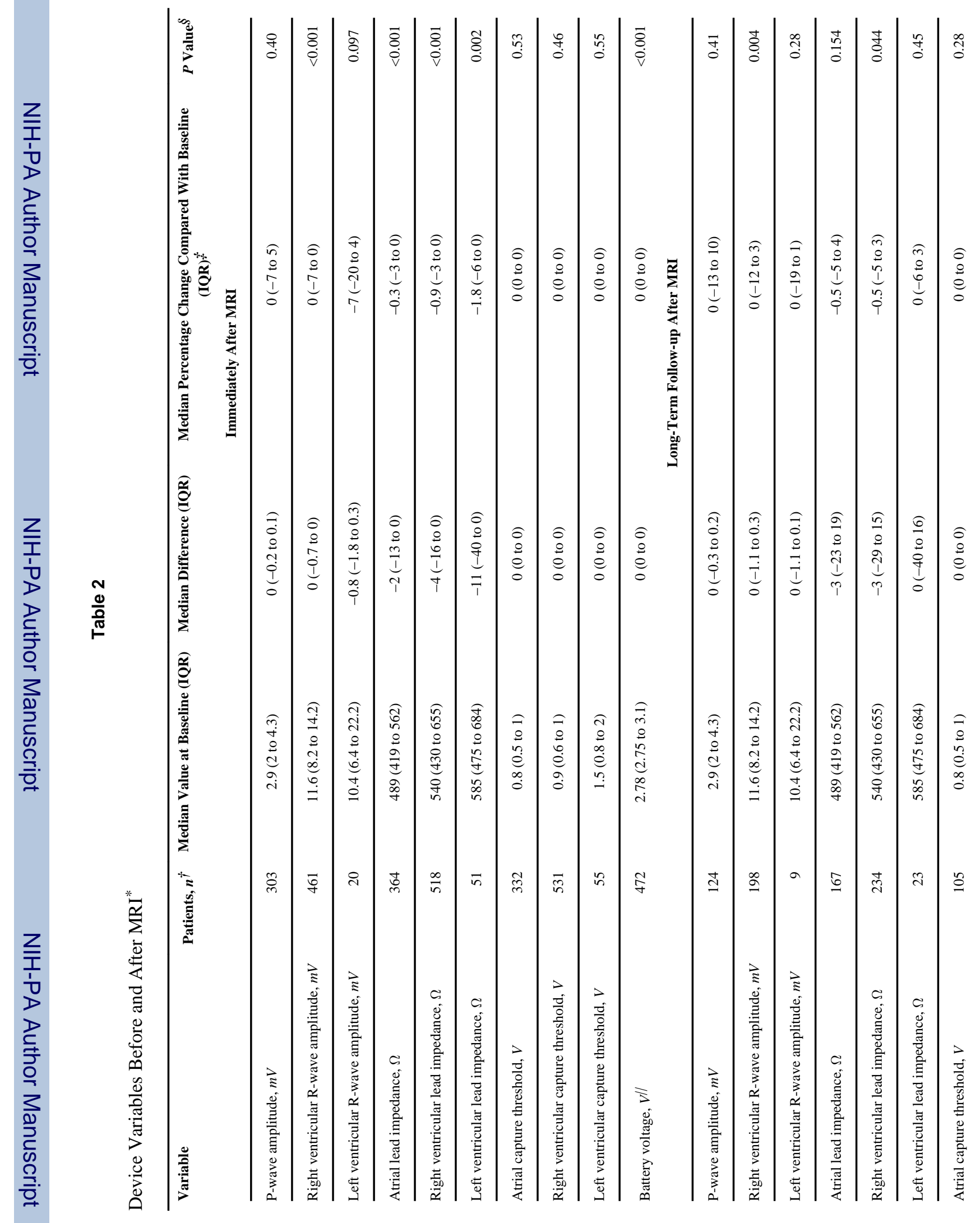


Nazarian et al.

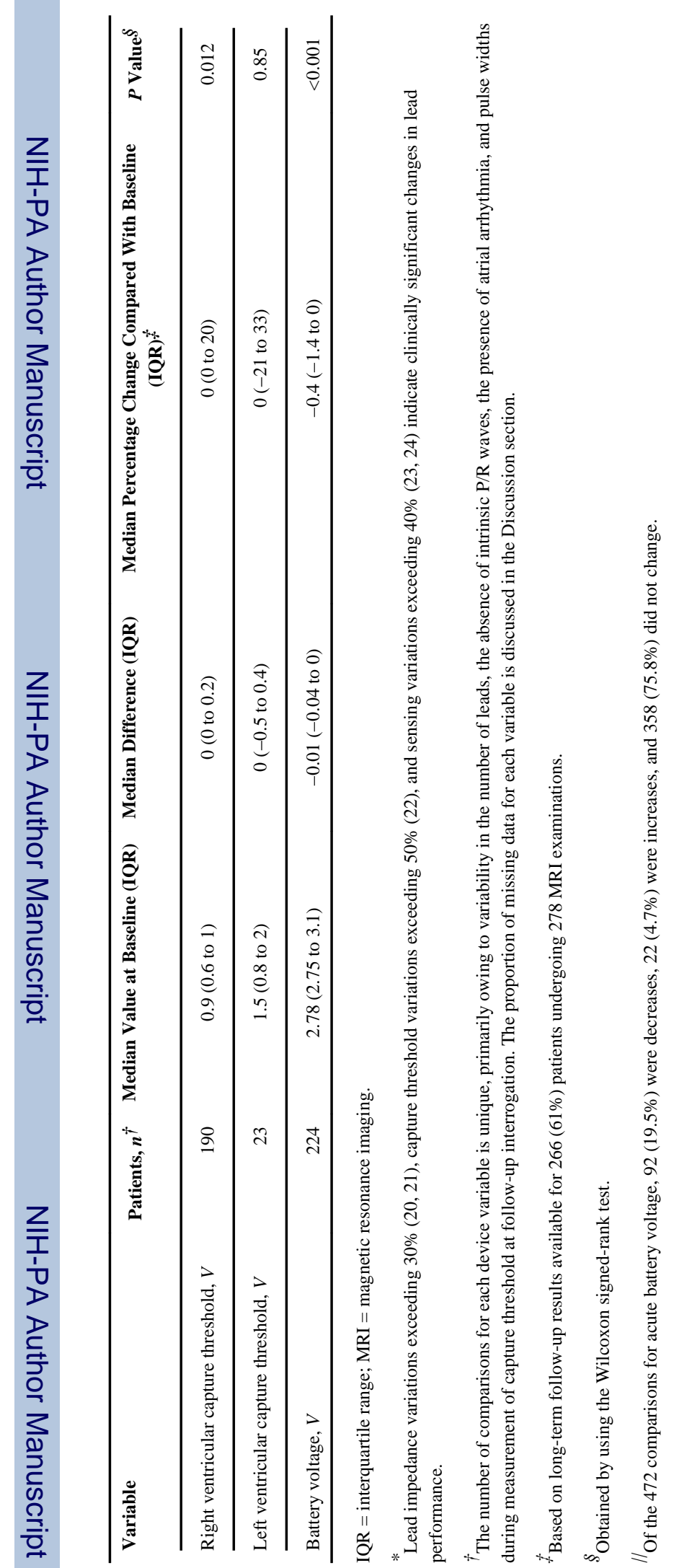

Ann Intern Med. Author manuscript; available in PMC 2015 February 23. 


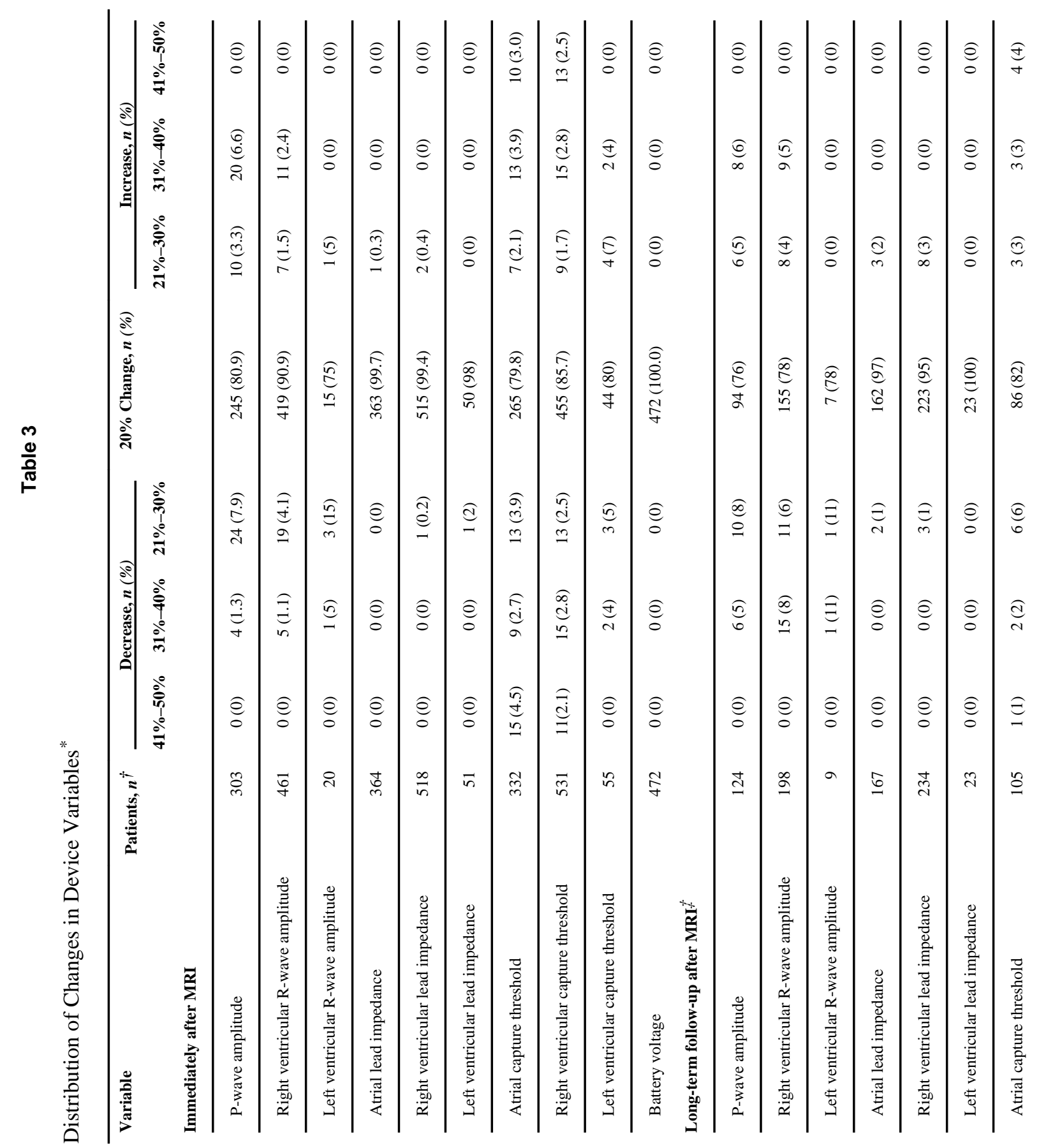




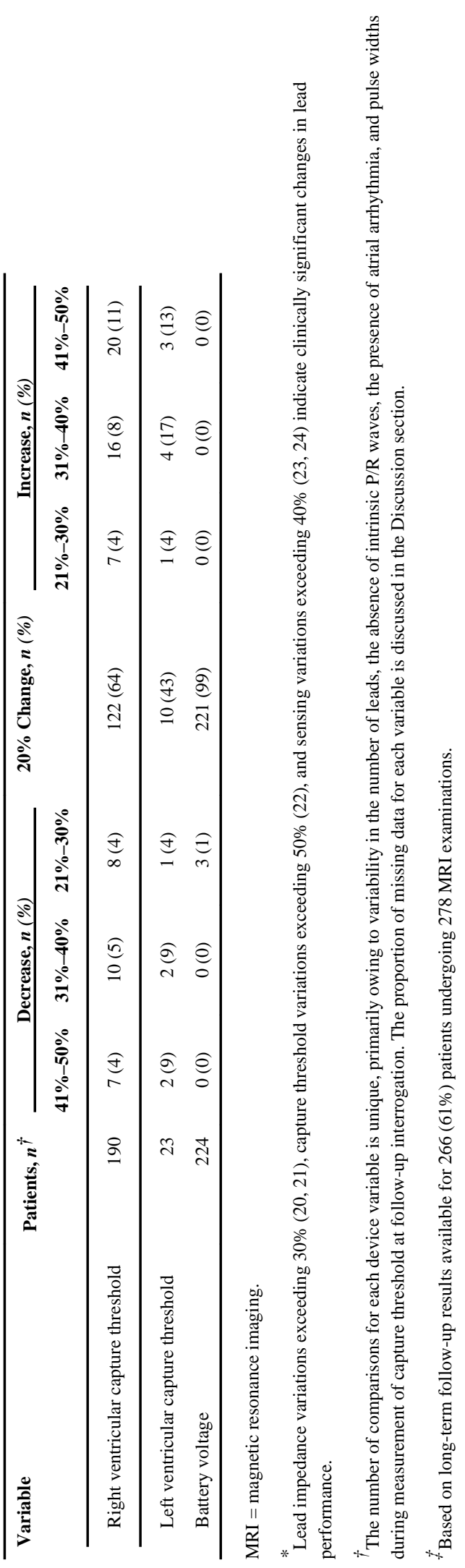


Table 4

Previous Studies of Clinical MRI in Patients With Permanent Pacemakers and ICDs

\begin{tabular}{|c|c|c|c|c|}
\hline Author, Year (Reference) & Patients, $n$ & Device & $\begin{array}{l}\text { MRI Field } \\
\text { Strength, } \\
T\end{array}$ & Finding \\
\hline Gimbel et al, 1996 (3) & 5 (1 pacemaker-dependent) & Permanent pacemaker & 0.5 & $\begin{array}{l}\text { 2-s pause noted on pulse oximetry in a } \\
\text { pacemaker-dependent patient whose } \\
\text { device (with unipolar leads) was } \\
\text { programmed to dual-chamber } \\
\text { asynchronous pacing; patients were } \\
\text { otherwise asymptomatic and did not } \\
\text { report any feeling of torque or heat. }\end{array}$ \\
\hline Sommer et al, 2000 (4) & 44 & Permanent pacemaker & 0.5 & $\begin{array}{l}\text { Pacing output inhibition or pacemaker } \\
\text { malfunction was not observed. }\end{array}$ \\
\hline Vahlhaus et al, 2001 (5) & 32 & Permanent pacemaker & 0.5 & $\begin{array}{l}\text { No significant changes in lead } \\
\text { impedance, sensing, or capture } \\
\text { thresholds immediately or } 3 \text { mo after } \\
\text { MRI; diminished battery voltage noted } \\
\text { immediately after MRI, with recovery } 3 \\
\text { mo later; temporary activation of reed } \\
\text { switch seen in } 12 \text { of } 32 \text { patients when } \\
\text { positioned in the center of the magnetic } \\
\text { field. }\end{array}$ \\
\hline Martin et al, 2004 (6) & 54 & Permanent pacemaker & 1.5 & $\begin{array}{l}\text { Statistically significant changes were } \\
\text { reported in } 9.4 \% \text { of leads; however, } \\
\text { only } 1.9 \% \text { required a change in } \\
\text { programmed output. }\end{array}$ \\
\hline Del Ojo et al, 2005 (7) & 13 & Permanent pacemaker & 2.0 & $\begin{array}{l}\text { No pacemaker inhibition, inappropriate } \\
\text { rapid pacing, or significant changes in } \\
\text { device variables were noted. }\end{array}$ \\
\hline Gimbel et al, 2005 (8) & 7 & ICD & 1.5 & $\begin{array}{l}\text { No changes in pacing, sensing, } \\
\text { impedances, charge times, or battery } \\
\text { status were observed; } 1 \text { ICD (Medtronic } \\
7227 \mathrm{Cx} \text {, lumbar spine MRI) } \\
\text { experienced a power-on-reset event. }\end{array}$ \\
\hline Sommer et al, 2006 (10) & 82 & Permanent pacemaker & 1.5 & $\begin{array}{l}\text { No inhibition of pacemaker output or } \\
\text { induction of arrhythmias noted; } \\
\text { increased capture threshold noted; in } 4 \\
\text { of } 114 \text { examinations, the troponin-I } \\
\text { level increased from a normal baseline } \\
\text { value to above normal after MRI ( } 1 \\
\text { elevation was associated with a } \\
\text { statistically significant increase in } \\
\text { capture threshold). }\end{array}$ \\
\hline Naehle et al, 2008 (35) & 44 & Permanent pacemaker & 3 & $\begin{array}{l}\text { No changes in lead impedance, pacing } \\
\text { capture threshold, or serum troponin-I } \\
\text { level. }\end{array}$ \\
\hline Mollerus et al, 2008 (12) & 37 & $\begin{array}{l}32 \text { permanent } \\
\text { pacemakers; } 5 \text { ICDs ( } 4 \\
\text { biventricular pacemaker) }\end{array}$ & 1.5 & $\begin{array}{l}\text { No changes in troponin-I levels or } \\
\text { pacing capture threshold. }\end{array}$ \\
\hline Naehle et al, 2009 (11) & 18 & ICD & 1.5 & $\begin{array}{l}\text { No device circuitry damage, changes in } \\
\text { lead variables, or troponin-I levels; } \\
\text { battery voltage decreased after MRI; } \\
\text { oversensing of electromagnetic } \\
\text { interference as ventricular fibrillation } \\
\text { occurred in } 2 \text { devices, but therapies } \\
\text { were not delivered. }\end{array}$ \\
\hline Naehle et al, 2009 (36) & 47 & Permanent pacemaker & 1.5 & $\begin{array}{l}\text { Repeated MRI ( } 171 \text { examinations on } 47 \\
\text { patients) was associated with decreased } \\
\text { pacing capture threshold and battery } \\
\text { voltage. }\end{array}$ \\
\hline
\end{tabular}




\begin{tabular}{|c|c|c|c|c|}
\hline Author, Year (Reference) & Patients, $n$ & Device & $\begin{array}{l}\text { MRI Field } \\
\text { Strength, } \\
T\end{array}$ & Finding \\
\hline Mollerus et al, 2010 (26) & 103 & $\begin{array}{l}105 \text { permanent } \\
\text { pacemakers; } 22 \text { ICDs }\end{array}$ & 1.5 & $\begin{array}{l}\text { Decreased sensing amplitudes and pace } \\
\text { impedances noted; other variables were } \\
\text { unchanged. }\end{array}$ \\
\hline Halshtok et al, 2010 (30) & 18 & $\begin{array}{l}9 \text { permanent } \\
\text { pacemakers; } 9 \text { ICDs }\end{array}$ & 1.5 & $\begin{array}{l}5 \text { power-on-reset events in } 2 \text { patients; } \\
\text { no other effects were reported, and } \\
\text { device replacement was unnecessary. }\end{array}$ \\
\hline Strach et al, 2010 (33) & 114 & Permanent pacemaker & 0.2 & $\begin{array}{l}\text { No changes in lead impedance, capture } \\
\text { threshold, or battery voltage. }\end{array}$ \\
\hline Burke et al, 2010 (34) & 38 & $\begin{array}{l}24 \text { permanent } \\
\text { pacemakers }(13 \\
\text { pacemaker-dependent); } \\
14 \text { ICDs }(4 \\
\text { biventricular) }\end{array}$ & 1.5 & $\begin{array}{l}\text { No device circuitry damage; } \\
\text { programming changes; inappropriate } \\
\text { shocks; failure to pace; or changes in } \\
\text { sensing, pacing, or defibrillator } \\
\text { thresholds. }\end{array}$ \\
\hline
\end{tabular}

ICD = implantable cardioverter-defibrillator; MRI = magnetic resonance imaging. 